in J. Thomas Rimer's chapter, particularly about how he saw in emakimono picture scrolls "technique of the cinema" (172), a topic I have written about in the context of film theorist Imamura Taihei. The last chapter, by Peter Leech, too, is groundbreaking in its ability to think through philosopher Kuki Shūzō's work beyond time and place. I too have done so previously with, admittedly, less convincing power.

Leech also acknowledges (albeit only in an endnote) Michael F. Marra's contribution to the field (410). This is a significant reference because what the volume and the field most critically lack is more engagement with writing on aesthetics in Japanese beyond the University of Kyoto. The main obstacle many scholars face in this regard is the absence of enough translations into English. Marra has provided a few translations of works by key aestheticians including Tokyo University's Ōnishi Yoshinori, and Imamichi Tomonobu. Still, other aestheticians, for example, Nishimura Kiyokazu and Otabe Tanehisa, among many others who continue to advance disciplinary study of Japanese aesthetics in their writings, should also be included.

In sum, New Essays in Japanese Aesthetics is a major contribution to Japanese studies. It widens the opportunity for non-Japanese specialists to engage with the paradox that is aesthetics itself, and not Japan as a topos. Chapters in the volume will surely intrigue scholars in many disciplines, as well as students, graduate and undergraduate alike. Despite its magnitude it does not exhaust the topic. On the contrary, it leaves much more to be desired, and puts forth a demand for more vigorous studies, more collaborative academic work on non-Western aesthetics, and for a broader inclusion of aesthetics into the larger field of Japanese studies.

\title{
The Tale of Genji: A Japanese Classic Illuminated
}

Edited by John T. Carpenter and Melissa McCormick. New York: The Metropolitan Museum of Art, 2019. 368pp.

\section{Reviewed by Marjorie Burge}

The Tale of Genji: A Japanese Classic Illuminated ran from March 5 through June 16, 2019 at the Metropolitan Museum of Art in New York 
City as the first major exhibition in North America to focus on art inspired by the classic literary work. The exhibition was organized by John T. Carpenter (Curator of Japanese Art, Metropolitan Museum of Art) and Melissa McCormick (Professor of Japanese Art and Culture, Harvard University), and brought together artworks inspired by The Tale of Genji spanning ten centuries, from the eleventh century through the present. This volume, as the accompanying catalogue compiled for the exhibition, is also the joint effort of Carpenter and McCormick, who seek to "celebrate the spectacular artistic tradition inspired by The Tale of Genji" and "trace the evolution and reception of its imagery over the course of ten centuries" (19). As the first such compilation available in English, this catalogue serves as a comprehensive guidebook to the art of Genji for amateurs and specialists alike. For those of us who were unable to attend the exhibition, this catalogue volume is a welcome substitute that offers an equally enriching experience, if at somewhat of a remove.

While the importance of The Tale of Genji in Japanese literary history is widely acknowledged, the 2019 Met exhibition and this catalogue highlight its pivotal place in the history of Japanese art. The works collected in this catalogue provide insight into the history of the reception of The Tale of Genji while presenting a cross-section of ten centuries of Japanese art history. This volume also features introductory essays for a general readership that are meant to aid in the interpretation of the featured artworks, as well as two appendices.

The first of four introductory essays is John T. Carpenter's "Learning the 'Women's Hand' in Heian Japan: Kana Calligraphy and The Tale of Genji," which engages both the discourse on kana calligraphy within Genji and the materiality of the Heian manuscript culture within which Genji would have originally circulated. This essay is an important starting point for the catalogue's exploration of the visual art of Genji, in that it aims to reconstruct the material experience of reading the original. The positioning of this essay at the head of the volume helps shape a particular narrative about Genji art: Carpenter's position is clearly that kana calligraphy is art, and therefore the original "visual art" of Genji is the tale itself. Carpenter raises compelling questions about the persistence of manuscript culture in Japan despite the availability of printing technology that help to bolster his larger point about the importance of the material experience of the kana script. This essay serves up a welcome reminder that our modern experience of reading Genji is many degrees removed from the "original," but also enriches our 
understanding of "kana culture" through a close reading of the discourse on calligraphic education for young women that appears within the tale.

The following essay, "Beyond Narrative Illustration: What Genji Paintings Do" by Melissa McCormick, is meant as an introduction to interpreting the paintings found in the catalogue section of the volume, which date from the thirteenth through the twentieth centuries. In the first part of her essay, McCormick outlines some common stylistic features peculiar to Genji paintings, including "Genji clouds" and "blown-off roofs," before moving into a discussion of scene selection that emphasizes understanding Genji scenes depicted in later artworks in terms of their patrons. The final section of McCormick's essay features detailed interpretations of several different painted versions of the "Battle of the Carriages" scene (from chapter 9, "Aoi") dated to the sixteenth and seventeenth centuries, where she focuses on explaining key differences in the depiction of this scene through reference to both patrons and evolving tastes. McCormick's essay helps to position the reader to recognize key aspects of Genji painting iconography, and through its close reading of several "Battle of the Carriages" paintings, invites the reader to apply a critical eye to Genji paintings from different eras based on the same scenes from the tale.

The third essay, "Evolving Iconographies of The Tale of Genji: Early Modern Interpretations of a Yamato-e Theme" by Kyoko Kinoshita (Professor of Japanese Art History, Tama Art University) is a thorough introduction to the world of Genji painting in the Momoyama and Edo periods. This essay serves to contextualize the large number of works in the volume that date to this era (found in chapters 4 and 5 of the catalogue). The first part of Kinoshita's essay focuses on two independent artists belonging to the late sixteenth and early seventeenth centuries, Tawaraya Sōtatsu (ca. 1570-ca. 1640) and Iwasa Matabei (1578-1650), who she argues were both able to cultivate a "unique and idiosyncratic approach" through techniques including the "abstraction, isolation of motifs, and enlargement of images" found in traditional Genji painting (62-63). In the second part of the essay, Kinoshita turns to a discussion of painters belonging to the shogunate-sponsored Kano school, who are responsible for a wide range of Genji-related artworks dating from the mid-seventeenth through the mid-nineteenth centuries. While Kinoshita presents a thorough picture of the sociocultural and professional contexts in which these painters worked, her focus is overwhelmingly on the painters, and unfortunately very little space is 
afforded for analysis of their works. This part of the essay is undoubtedly a valuable introduction to succeeding generations of Kano painters, but because it is less tethered to a discussion of works about Genji, it feels out of sync with the first part of the essay and with the volume as a whole.

The fourth and final essay, "Genji and Good Fortune: Bridal Trousseaux in the Age of the Tokugawa Shoguns," by Monica Bincsik (Associate Curator for Japanese Decorative Arts, Metropolitan Museum of Art), explores the prominent place of Genji iconography on objects that made up the bridal trousseaux of elite women in the Edo period. This essay is a crucial companion to chapter 6 of the catalogue, which features a variety of Genji-themed material artifacts. Bincsik's essay provides an overview of marriage customs among the warrior elite under the shogunate while introducing the variety of objects found in a typical bridal trousseau. In her exploration of Genji-themed objects found in the trousseau of the highest-ranking brides, Bincsik focuses first on elaborate lacquerware objects from the trousseau of Chiyo-hime (1637-1699), the eldest daughter of shogun Tokugawa Iemitsu, a significant contingent of which feature iconography based on the twenty-third chapter of Genji, "Hatsune." Bincsik then goes on to explore incense-related artifacts both within The Tale of Genji and as part of Edo-period bridal trousseaux. Finally, Bincsik discusses the depiction of scenes from Genji on garments, and particularly on kosode robes, in the Edo period. At several points in her essay, Bincsik hints at the prominence of Genji themes in bridal objects as being connected to the importance of Genji for women's education in the Edo period, and the ways in which Genji themes were invoked as a means of re-creating the elegant cultural sophistication of the Heian period. This final essay is an important contribution in priming the reader to think about Genji art as not just the paintings of the Tosa and Kano schools but as something that extended into the everyday material lives of elites.

The remainder of the volume consists of the exhibition catalogue. The catalogue features a total of 106 different entries which are organized into seven "chapters." Each chapter features a brief introduction explaining the theme around which the artworks are curated therein, and each artwork is accompanied by an extensive explication of its content and significance by Carpenter, McCormick, Kinoshita, or Bincsik.

Chapter one, "Heian Court Culture and the Transmission of the 
Tale," is a collection of manuscripts, emaki, and illustrated editions of the tale dating from the mid-thirteenth through the mid-seventeenth centuries. This chapter includes examples of the earliest Genji manuscripts as well as excerpts from related works such as the Murasaki Shikibu nikki emaki (Illustrated Diary of Murasaki Shikibu), a page from Murasaki shikibu $s h \bar{u}$ (The Poetic Memoirs of Murasaki Shikibu) in the hand of Fujiwara no Teika, and several excerpts from The Collected Works of Bai Juyi in the hand of the renowned calligrapher and contemporary of Murasaki Shikibu, Fujiwara no Yukinari (972-1027). The chapter is completed by sections from illustrated versions of Genji dating to the Momoyama and Edo periods.

Chapter two, "Ishiyamadera and the Buddhist Veneration of Murasaki Shikibu," is focused on works associated with the legend of the miraculous inception of The Tale of Genji at Ishiyamadera temple and spiritual aspects of Genji's reception. Included are the main image of the Ishiyamadera temple, a Lotus Sutra scroll that may have been used in a "Genji offering" (aimed at saving Murasaki Shikibu from the tortures of hell), sections of Ishiyamadera engi emaki (Illustrated legends of Ishiyamadera) dating to the fourteenth and fifteenth centuries, and several portrait-icon hanging scrolls of Murasaki Shikibu dating from the sixteenth, seventeenth, and eighteenth centuries from the temple's collection. This chapter provides a thorough impression of the impact of the Ishiyamadera temple legend and Buddhist belief on evolving narratives about Murasaki Shikibu and her tale through the centuries.

Chapter three, "Monochrome Genji Pictures and the Conventions of Hakubyo" features works in the hakubyo (ink-line drawing) style, including both monochrome paintings that mimic professional polychrome paintings and works by amateur artists. This chapter contains examples of the hakubyo mode ranging from Kamakura-period illustrated booklets and scrolls depicting imaginary poetry competitions, to Muromachi-period amateur handscrolls depicting scenes of poetic composition within the tale, to Edo-period professional paintings that combine the "ink painting sensibility" of the kanga (Chinese style painting) tradition with the "gold and silver refulgence" of the yamato-e (Japanese style painting) (155).

Chapter four, "Imagining Genji through Tosa-School Paintings," traces the lineage of polychrome court paintings produced by the Tosa school in the sixteenth and seventeenth centuries. As official court painters, the Tosa school scions were responsible for developing a style 
of painting that "blended the rich mineral pigments and gold of Japanesestyle painting (yamato-e) with the calligraphic ink-line effects of Chinese-style painting (kanga)," while they also transformed Genji pictures from the intimate handscrolls of the Heian and medieval eras into "large-scale works on folding screens and sliding doors" (167). The works curated in this chapter trace this development, beginning with a section of a rare polychrome handscroll from the medieval period before enumerating a number of works attributed to Tosa school painters, including small-scale paintings on fans and in albums (such as \#38, the 1510 Genji monogatari gajo [The Tale of Genji album] held by the Harvard Art Museum, the entirety of which has been published separately in Melissa McCormick's 2018 "The Tale of Genji”: A Visual Companion), and large-scale paintings on folding screens and sliding doors, including the "Battle of the Carriages" by Tosa Mitsumochi, discussed in detail in McCormick's essay.

Chapter five, "Innovations and Interventions in Later Genji Painting," traces the development of Genji painting beyond the Tosa school, beginning with the work of Kano school painters and machi eshi (i.e., independent painters such as Tawaraya Sōtatsu, whose work is discussed at length in Kinoshita's essay) in the sixteenth and seventh centuries, through the Nihonga painters of the Meiji and Taishō periods. Notably included are four sections of the Maboroshi no Genji monogatari emaki (Phantom Genji scrolls), a mid-seventeenth century work, only partially extant, that includes "the full text of the tale alongside sprawling painted compositions,"'(214; \#54 through \#57) and the copies of the twelfth-century Genji monogatari emaki (Illustrated Genji scrolls) made by Tanaka Shinbi in the early twentieth century (\#60).

Chapter six, "An Elegant Lifestyle Inspired by Genji: Lacquers, Garments, and Games," is a thorough exploration of the material culture of Genji. While the curation is focused on including objects such as lacquerware, robes, and game pieces which depict scenes from the tale, this chapter also includes objects that are central to material life within the tale, such as musical instruments, incense utensils, mirrors, and writing boxes, as well as masks and costumes used in the performance of the Genji-derived Nō play Aoi no ue (Lady Aoi). This chapter serves to flesh out the catalogue's narrative of the artistic reception of Genji by looking beyond illustration and painting toward how scenes from the tale came to adorn everyday objects used by the elite.

Chapter seven, "Genji and Print Culture: From Ukiyo-e to Manga," 
covers popular depictions of the tale in the early modern and modern periods. The popular reception of Genji in the early modern period was made possible by the publication of the first woodblock-printed version with illustrations, E-iri Genji monogatari (The illustrated Tale of Genji), included here as \#91. The availability and accessibility of this version spurred popular interest in the tale; in response, artists in the emerging ukiyo-e style produced a number of works that transposed characters from the tale into the "modern" world (a device known as yatsushi). These works are well-represented in this chapter (e.g., \#92 and \#93), as are parodic works such as those of Utagawa Kuniyoshi (\#101 and \#102), which juxtapose characters from Genji with characters from the contemporary theater. Finally, the chapter concludes with popular illustrations from the Meiji and Taishō periods (including those from Yosano Akiko's 1912 modern Japanese translation of the tale; \#105) and the contemporary manga work Asaki yume mishi (Fleeting Dreams) (\#106). While much of the catalogue has been focused on Genji depictions that were consumed exclusively by high-ranking aristocrats and members of the warrior class, this chapter serves to show how Genji became part of the popular imagination in the early modern and modern eras.

The catalogue is an exhaustively curated collection of works that tell the story of Genji's genesis and reception through a variety of beautifully reproduced images. In including some works not part of the exhibition, Carpenter and McCormick clearly prioritized presenting a comprehensive history of Genji representations in this volume. The "captions" that accompany each work go well beyond a typical museum label in introducing the context and discussing the formal features of each artwork. The accessibility of these captions appears to be designed with the non-specialist in mind, creating a smooth, engaging reading experience from entry to entry.

Following the catalogue section are two appendices. The first of these, a guide to shinden architecture, is a concise guide to the physical spaces of a Heian aristocratic residence. This appendix would be a welcome addition to any Genji translation, but it is especially useful here for parsing some of the paintings in the catalogue, particularly those which employ the "blown-off roof" technique. The second appendix offers a detailed guide to a pair of six-panel folding screens from the late seventeenth century known as Genji monogatari zu byōbu (Fifty-Four Scenes from The Tale of Genji) (\#59), which features one scene from 
each chapter of the tale. This not only enriches the reader's experience of this particular painting, but serves as a means of refreshing one's knowledge of the tale in order to better engage with the other works in the catalogue.

The Tale of Genji: A Japanese Classic Illuminated is the sort of volume every teacher of Japanese literature will want on their shelf. This volume features high-quality, vibrant reprints of a comprehensively curated collection of Genji-related images, along with incisive introductory essays that are just the right length for a syllabus. Indeed, for those of us who teach Genji courses regularly, it is the long-awaited visual companion volume to the tale. In addition, for those of us outside the field of art history, the four introductory essays help provide the tools to make sense of the images in a manner that will aid in our sharing of them with our students. These features ensure that this volume will remain an indispensable resource for teaching The Tale of Genji for decades to come.

The Kanji Code: See the Sounds with Phonetic Components and Visual Patterns.

By Natalie Hamilton. Sydney: Ocha Press, 2019. 275 pp. $\$ 24.95$

\section{Reviewed by \\ Sachiko Matsunaga}

This is a guidebook for nonnative learners of Japanese that covers a subset of commonly used kanji (Chinese characters) and presents innovative learning strategies that focus on the sounds of kanji, particularly their on (Sino-Japanese) readings. The author's approach is unique given that many kanji guidebooks for such learners typically focus on pictorial and/or mnemonic approaches in helping remember the shapes and meanings of kanji while providing little or no help in learning to read them in Japanese. By introducing systematic ways to learn common on-readings of kanji (via identification of phonetic hints within kanji and application of a visual approach to learning on-readings), the 